\title{
Trabajando la Cultura: sobre la construcción de la identidad negra en Aguablanca, Cali ${ }^{1}$
}

\author{
Peter Wade
}

\begin{abstract}
The dualism in social science between practice and discourse has begun to be questioned, amongst others, by perspectives that are trying to overcome the division between culture and politics. This questioning can be supported by an examination of the tension between culture as a human activity of presence in the world, in which there is a unification of the material and symbolic, and culture as a manufactured object in the context of hegemonic constructions of culture. This article analyzes this tension in relation to the activities of black youths in Aguablanca, Cali, who use rap to create a cultural identity as a way of life and at the same time create their culture as an object designed to facilitate their presence in the market, the state and the NGOs. The local state and the voluntary sector also work on culture as more limited set of expressions, seeking to depoliticize it.
\end{abstract}

Las aproximaciones de la teoría antropológica hacia los movimientos sociales contemporáneos han estado obstaculizadas por dos divisiones conceptuales que se sobreponen. La primera de ellas es el viejo dualismo entre lo material y lo simbólico que, aunque ha dejado de ser fuente de desacuerdos desde los debates de la década del setenta, todavía tiene alguna influencia. Una de las razones de su persistencia es la segunda división entre la "cultura" como

\footnotetext{
${ }^{1}$ La investigación en Cali fue financiada por la Fundación Nuffield y se llevó a cabo durante un poco más de dos meses en 1997. También hice unas entrevistas adicionales en julio de 1998, con financiación del Fondo de Apoyo para Investigaciones de la Universidad de Manchester. En Cali agradezco al CIDSE de la Universidad del Valle y a Fernando Urrea. Agradezco a mis colegas Karen Sykes, Mark Harris, Anna Grimshaw y Richard Werbner por sus comentarios a un primer borrador para este artículo. Agradezco a Arturo Escobar y a cuatro pares anónimos por sus valiosos comentarios en borradores anteriores.

* Traducción de Wilhelm Londoño, revisión de Enrique Jaramillo. Título original en inglés: "Working Culture. Making Cultural Identities in Cali, Colombia", en: Current Anthropology, Vol 40. Nro. 4, Agosto-Octubre de 1999, pp: 449-471. Agradecemos al Editor de la Universidad de Chicago la autorización para esta publicación. Asimismo, al profesor Peter Wade por conceder el permiso con prontitud. Los fondos para realizar esta traducción, provinieron de la Secretaría de Salud Departamental del Valle del Cauca y del Hospital Isaías Duarte Cancino. Agradecemos, de estas instituciones, a Alberto Campo, Javier Parga, Alejandro Varela, y Flor Nayda Cuadros. La exactitud o no de la traducción no es responsabilidad del autor ni de la editorial de la Universidad de Chicago.
} 
un conjunto de representaciones (a menudo mercantilizadas) y la "cultura" como una forma de vida, un estar-en-el-mundo, un conjunto de prácticas. Estas divisiones conceptuales se sobreponen en la medida en que la "cultura" como representación, es también la cultura como símbolo. Ambos, los objetos materiales y los discursos, pueden estar implicados el uno en el otro, pero también pueden actuar como símbolos de la cultura entendida como una forma de vida — de prácticas corporalizadas, de trabajo, que permiten la creación de esos objetos y esos discursos. En estas prácticas, lo material y lo simbólico están indisolublemente ligados. Sin embargo, la emergencia generalizada de las "culturas" como representaciones objetivadas seduce tanto a antropólogos, como a no-académicos, a privilegiar lo simbólico. La "Cultura", ya sea como forma de vida o como representación objetivada, existe en un mundo jerárquico en donde ciertas versiones son hegemónicas. Una de nuestras tareas sera rastrear las dinámicas de esas dos modalidades de la cultura y examinar cómo esas dinámicas participan en operaciones de poder en sus formas hegemónicas e ideológicas.

\section{El dualismo de lo material y lo simbólico}

Por largo tiempo los debates sobre el dualismo entre lo material y lo simbólico han sido característicos del dominio teórico en filosofía, arte, y ciencias sociales. Para algunos la discusión ya ha sido resuelta: Bauman (1973) y Bourdieu (1977) en diferentes contextos, proponen aproximaciones que buscan ir más allá de las distinciones subjetivo/objetivo; los Comaroffs (1992: 30) ven la cultura como un "campo semántico cambiante" cuyas formas son "indivisiblemente semánticas y materiales”. Sin embargo, la persistencia del debate en cuestión indica que el dualismo permanece. Las aproximaciones post-estructuralistas a la sociedad y la cultura hicieron un esfuerzo por resolver el problema enfocándose en la constitución discursiva de las realidades materiales y en la materialidad del discurso, pero algunos de tales enfoques fueron criticados por replegarse en el discurso y perder contacto con la materialidad (véase e.g. Lave et al. 1992; Shilling, 1993; Turner, 1994; Butler, 1993; Comaroff y Comaroff, 1992: 40). En arqueología y geografía, las aproximaciones fenomenológicas buscaron reconciliar las abstracciones positivas con las nociones de sentido en el entendimiento del espacio y el paisaje (e.g. Tilley, 1994; Tuan, 1977). En antropología, las aproximaciones culturalistas o interpretativas han sido un constante objetivo de las críticas materialistas como las de Wolf (1982). Asimismo, Mintz (1985: 157-58) cualifica el enfoque de Geertz sobre "las redes de significación" preguntando cómo tales redes son producidas en instancias históricas específicas y por quién. En un reciente ensayo sobre la constante importancia de la obra de Marx para la antropología, Roseberry 
(1997: 29) también llamó la atención sobre este problema señalando que otorgar demasiada prioridad a las "convenciones narrativas del texto" tal vez resulte en la desaparición de lo que Marx llamó los "hombres (sic) de carne y hueso". En una revisión de las políticas de la identidad cultural, Hale (1997: 570) señala que los debates entre las "innovaciones teóricas postmodernas y las reafirmaciones materialistas" se han polarizado y que algunos trabajos recientes se esfuerzan por ir más allá de las mismas.

El concepto de "cultura" en sí mismo, ha estado atrapado por la tensión propia de este dualismo. Para la antropología, este concepto tradicionalmente ha denotado toda una forma de vida, antes que sólo un conjunto de expresiones estéticas y simbólicas, ya sean elitistas o de clases populares (Williams, 1961: 41-43; 1988: 91). Sin embargo, es evidente que especialmente en el siglo $\mathrm{XX}$ se ha presentado un indiscutible deslizamiento entre estos dos sentidos. Reflexionando sobre el aparente desarrollo autónomo de la "cultura" en un mundo post-moderno, junto a la proliferación de información e imágenes, Joel Kahn señala que la "palabra cultura se encuentra en boca de todos", y añade que "en la proliferación de simulacros, nuestras vidas se han vuelto totalmente culturalizadas" (1995: ix). No obstante, desde un punto de vista estrictamente antropológico, la vida de todos los seres humanos está siempre "completamente culturalizada". ¿Sino es así, de qué otra forma podría ser?

Si miramos por un momento a la teoría de los movimientos sociales, detectaremos un problema similar: un intento coherente por superar la brecha entre lo material y lo simbólico y su aparente permanencia. Las teorías sobre "nuevos" movimientos sociales promueven "una transformación fundamental en la naturaleza de la práctica y la teorización de la política" (Escobar y Álvarez, 1992: 3). La política basada en las divisiones de clase ha sido eclipsada por una nueva definición en la cual "una multiplicidad de los actores sociales establecen su propia presencia y una esfera de autonomía en un espacio social y político fragmentado." Esas nuevas teorías están claramente conectadas con las nociones sobre la fragmentación y la globalización en un mundo post-moderno o con los cambios hacia una sociedad post-industrial. ${ }^{2}$ En la teoría de los movimientos sociales, el dualismo material/simbólico se ubica en la tensión entre los llamados modelos de movilización de recursos, sustentados en la noción de actores que agrupan recursos a través del calculo instrumental, y las aproximaciones que se centran en la "identidad como el primer paso para explicar las decisiones estratégicas" (Fowerake, 1995: 12; Escobar y Álvarez, 1992: 5-6).

\footnotetext{
${ }^{2}$ Ver Thompson 1992, sobre el post-modernismo en general; Beverley y Oviedo (1995) sobre este cambio en Latinoamérica y Foweraker, 1995: 10-11y Escobar, 1992: 71 relacionado con el análisis de Touraine sobre el cambio hacia un orden post-industrial.
} 
Tanto Foweraker como Escobar buscan reconciliar la mirada sobre la identidad con la atención sobre los recursos. Foweraker (1995: 13) considera que es posible "construir una síntesis de las dos aproximaciones que aborde los movimientos sociales de manera tanto expresiva como instrumental". En esta síntesis, la identidad es compleja: no se trata simplemente de que "existe" como una "precondición de una acción estratégica". Tampoco la identidad se construye en su totalidad a través de acciones estratégicas. En vez de ello, la locación social y la experiencia compartida de los actores proporcionan "materias primas" para la identificación, mientras "los procesos de organización y la decisión estratégica contribuyen crucialmente a construir y formar la identidad" (Foweraker, 1995: 21-23). En una vía similar, frente a los enfoques más tradicionales sobre los movimientos sociales, Escobar busca tomar en cuenta "los intereses culturales de la acción colectiva" (Escobar, 1992: 72) y ver los movimientos sociales "igual y conjuntamente como luchas por los sentidos asimismo como por la condiciones materiales" (1992: 69).

Esto no es simplemente una cuestión de combinar las dos aproximaciones, sino de reconocer la naturaleza fundamentalmente discursiva de todas las prácticas sociales (1992: 78): los sentidos y los intereses están constituidos discursivamente, y la cultura y lo político se le superponen. Álvarez, Dagnino y Escobar (1998), persiguen esta agenda, e invocando una vieja premisa feminista, abogan por mirar lo personal como político, enfatizando la necesidad de entender lo político como "más que sólo un conjunto de actividades específicas (votar, simpatizar, hacer lobby) que ocurren en espacios delimitados e instituciones tales como el parlamento y los partidos" (1998: 10-11). Discutiendo "la cultura política de la protesta social," Fox y Starn (1997:3) plantean también lo "inextricable de la cultura de la política y las políticas de la cultura en la movilización”.

Usando una noción similar de "políticas culturales", Álvarez et al. señalan que, aunque es tentador "restringir el concepto [...] a los movimientos que son claramente culturales," de hecho, "en América Latina hoy, todos los movimientos reivindican una política cultural" (1998: 6). La cultura es política porque "los significados son constitutivos de procesos, que implícita o explícitamente, buscan redefinir el poder social" (1998: 7). Ellos se distancian así mismos de una noción de política cultural que sólo ve "luchas despersonalizadas por significados y representaciones", y buscan en vez de ello hacer explícitos los lazos entre las representaciones y el poder tal como se manifiesta en "las prácticas, las acciones concretas, de los movimientos sociales de América Latina” (1998: 6). Veo este proyecto como parte de lo que Hale (1997: 570) llama la "la salida más radical" en las teorizaciones en ciencias sociales, lejos de la mera "síntesis de la tesis materialista y de la antitesis discursiva" y hacia la exploración de una 
"nueva política de la teoría” que esté políticamente circunscripta a una práctica reflexiva.

Deseo construir sobre esas iniciativas en una dirección algo diferente; una sugerida por el hecho de que, a pesar de los avances conseguidos para socavar las distinciones entre cultura y política o identidad y recursos, esas distinciones tienen la tendencia a reaparecer. Escobar, por ejemplo, utiliza la división de Fiske entre "cultura (significación) y política (acción)" (1992: 76), en la cual se considera la cultura como sinónimo de "significado" implicando una separación de la política —aun cuando se reconoce que los dos dominios se entretejen en una compleja relación, en la práctica, se mantiene la división conceptual. Al respecto, en el texto de Álvarez et al., me interesa señalar la idea de que algunos movimientos sociales son más “claramente culturales” que otros. ¿Qué significa esto? Es evidente que desde un punto de vista antropológico, todo movimiento social, de hecho toda la vida humana, es enteramente cultural. Pero pareciese que lo "cultural" es entendido en el sentido de representaciones, ideas, símbolos, etc. que están implícitamente diferenciados de alguna cosa más ("política”), incluso aunque los dos se muestren como interrelacionados. En este punto, es claro que Álvarez et al. difícilmente están solos. La división es reiterada por toda la problemática marxista (y anti-marxista), que ha sido generalmente caracterizada por plantear la pregunta por la relación, determinante o no, entre lo material y lo simbólico. La mirada antropológica debe insistir en que lo económico, lo político, lo familiar, lo artístico y lo identitario están igualmente marcados por la cultura y que son implementados en formas que tienen significado y valor simbólico. Como insistía Raymond Williams hace mucho tiempo, la cultura de la opera es tan material como una barra de hierro (i.e. cargada de sentido). ${ }^{3}$ Este concepto inclusivo de cultura existe en tensión con la fragmentación de la cultura - en la política, los símbolos, las prácticas, etc._- que se relaciona a menudo con las desigualdades del poder, especialmente bajo el capitalismo. Sugiero que podemos avanzar manteniendo la mirada atenta en la tensión entre la unidad y la fragmentación de la actividad humana.

En un nivel, el enfoque por el que abogo considera a la actividad humana como una "unidad necesaria" (Rosberry, 1997: 29). Esta unidad puede ser analizada, siguiendo a Marx entre otros, a través de "lo que los seres humanos dicen o imaginan, las maneras cómo ellos se narran, los seres humanos de carne y hueso". En otras palabras, a través del discurso y la práctica. Sin embargo, desde

\footnotetext{
${ }^{3}$ Ver Williams: "El arte está allí, como actividad, junto con la producción, el intercambio, la política, la crianza de familias. Para estudiar las relaciones en la forma adecuada debemos hacerlo en forma activa, viendo todas las actividades como formas de actividad humana particulares y contemporáneas"; "Todos los actos de los seres humanos constituyen una realidad general dentro de la cual el arte, y lo que ordinariamente llamamos sociedad, están indisolublemente ligados" (1961: 69).
} 
mi punto de vista es importante notar que esos dominios, aspectos o dimensiones no son inherentes al objeto de análisis en sí mismo, sino que son producidos por el observador. Pensar lo material como separado de lo simbólico, aún si se ubican dentro de una relación "dialéctica" o de "mutua constitución", es una forma profundamente arraigada del pensamiento occidental y no ha sido suprimida de las teorías académicas: la distinción entre palabras y acciones funciona casi como una segunda naturaleza. Podría ser más útil pensar cada decir o imaginar, como un hacer, y cada hacer como un decir a la vez que un imaginar. Esto no es lo mismo que afirmar que cada práctica tiene "aspectos" instrumentales y simbólicos. Por el contrario, es afirmar que todas las actividades humanas son significativas y que todos los significados humanos tienen materialidad o son materialmente activos. Esta última parte de la formulación es la más interesante. La primera, por su puesto, tomada en su sentido más simple es un lugar común en antropología. Algo ya señalado por Sahlins (1976) y, desde otro punto de vista, también señalado en la teoría post-estructuralista es que todas las prácticas materiales son simbólicamente constituidas. Desde mi punto de vista, no se trata de ver la producción de sentido como constreñida por la lógica de la producción material, ni viceversa: ambas esferas de producción son parte de la misma "unidad necesaria" de la actividad humana o de trabajar en el mundo. "Imaginar una comunidad nacional" es un acto material lleno de significado que en efecto constituye esa comunidad, al igual que comprar un diario nacional o matar en el nombre de la nación.

Hay diversas aproximaciones teoréticas que proveen bases útiles para la dirección que estoy asumiendo. La más desarrollada es la fenomenología, que ha producido un impacto en las ciencias sociales en disciplinas como la antropología, la geografía, la arqueología, la psicología y la sociología. Este enfoque, que se esfuerza por superar los dualismos sentido/acción y mente/cuerpo, ha sido desarrollado fuertemente en antropología por Tim Ingold (1991, 1992, 1995; además Jackson, 1989; Csordas, 1994). Desafiando a los cognitivistas y a los enfoques interpretativos de la cultura (como el de Clifford Geertz), Ingold sostiene que a pesar de sus evidentes diferencias, esos enfoques convergen en dividir a los seres humanos en un elemento orgánico y natural que necesita el trabajo material para subsistir y un elemento cultural, cognitivo, que invierte el flujo amorfo de la experiencia por medio de la estructura y el significado. La mayoría de los enfoques en antropología asumen que los seres humanos - y esto es lo que define su humanidad —organizan el mundo natural según los modelos de la cultura: es, en este sentido, que los mundos culturales son "construidos". Esta perspectiva, denominada por Ingold (1995) la "perspectiva del construir",

\footnotetext{
${ }^{4}$ En inglés, "Bulding perspective" (nota del editor).
} 
divide el sentido de la práctica, haciendo del primero un plano previo que guía la actividad en el mundo. El desafío planteado por Ingold descansa en la idea fenomenológica de que el ser humano es un ser integro, por ello la totalidad del organismo humano está involucrado en la percepción al mismo tiempo, no sólo "la mente". No hay esquemas o modelos culturales preexistentes que den forma al flujo de la naturaleza. Los seres humanos y el medio ambiente en el que viven son mutuamente constituidos, y las formas culturalmente modeladas de hacer las cosas surgen de esta relación dinámica. "La percepción es un modo de involucrarse con el mundo, no un modo de construcción del mismo"; las personas no "construyen" sus mundos, sino que habitan dentro de ellos (Ingold, 1991: 15). Tomando como modelo las teorías de Heidegger y Merleau-Ponty, Ingold (1995: 77), Ingold denomina este enfoque la "perspectiva del habitar". Esta perspectiva considera las formas culturales no como algo "traído a los contextos medioambientales del desarrollo" desde esquemas genéticos o cognitivos, sino como generadas dentro esos contextos "en los desplazamientos de los seres humanos (o de animales no-humanos), produciendo compromisos prácticos con los componentes de sus entornos." Los enfoques fenomenológicos permiten lidiar con la especificidad de la actividad humana, porque buscan sobreponerse a la división entre mente y cuerpo, sentido y acción. El sentido se genera en y a través de una participación activa con el mundo, e influye esa actividad como un todo. Como lo señala Jackson: "el significado no debería ser reducido a un signo que yace en un plano separado por fuera del inmediato domino de un acto" (1989: 122).

El énfasis de Ingold en el compromiso práctico es valioso porque mientras los términos usados en los enfoques fenomenológicos — percepción, habitar, estar-en-el-mundo- parecen evocar cierta pasividad, las actividades humanas en el mundo son vitales. La noción de construcción tal vez sea una metáfora pobre en la medida en que sugiere ejecutar un modelo o un esquema previo, pero de alguna manera captura el esfuerzo que demanda estar-en-el-mundo. Esto es importante, porque deseo poner en un primer plano los esfuerzos y el trabajo que la gente hace. Utilizo aquí, la palabra "trabajo" en un sentido amplio. Inspirado en una visión marxista de la acción en y sobre la naturaleza como un aspecto fundamenta de la humanidad y la sociabilidad de las personas, me aparto de una definición limitada que se centran únicamente en el trabajo "material" entendido como la transformación de la tierra o en la producción de artefactos. Para mí, hablar y pensar también son trabajos, es decir, actividades humanas comprometidas con y transformadoras de la naturaleza y el mundo social. En un nivel vulgar, ambas actividades necesitan energía para sostenerse. Trabajar la

\footnotetext{
${ }^{5}$ En inglés, "Ddwelling perspective" (nota del editor).
} 
tierra y hablar sobre ella pueden ser actividades localizadas en diferentes espacios de las relaciones sociales y pueden tener diferentes impactos en ellas, pero no son categorías opuestas como lo material es a lo simbólico. Ambas son formas de compromiso con el mundo, o formas trabajo en el mundo, simultáneamente significativas y materiales. Esta concepción de lo que es el trabajo se acerca a lo que Wagner (1981: 24-25) considera como típicamente melanesio, o en un sentido más amplio, la manera "tribal" de la actividad humana, en la que "trabajo" puede ser cualquier cosa desde desyerbar un jardín, tomar parte en un festín o engendrar un niño." Sostengo que esta perspectiva no debería aplicar solo al mundo "tribal", debería ser un punto de partida antropológico.

Una segunda tendencia teórica, relacionada con la primera, se ocupa de la corporalidad. Para Judith Butler (1993), por ejemplo, las teorías sobre el cuerpo sexuado y genérico como una "construcción social" (incluyendo sus obras tempranas), parecen disolver la materialidad del cuerpo, y ella no está sola en esta preocupación (véase Shilling, 1993; Csordas, 1994; Turner, 1994; Comaroff y Comaroff, 1992: 40). Butler intenta maniobrar entre el constructivismo radical (en el que los significados preexistentes construyen la materialidad) y el esencialismo (en el que una materialidad dada con anterioridad define algunos significados básicos) hablando en términos de "restricciones constitutivas". Las restricciones no sólo limitan alguna performatividad inherente o agencia humana, sino que son "la condición misma de la performatividad"; ellos la alimentan y la mantienen (1993: 94-95). ${ }^{6}$ Henrietta Moore también trató de teorizar sobre la materialidad de la corporalidad; retomando a Bourdieu (1977), ella argumenta que "la corporalidad es un proceso y [...] el cuerpo nunca está terminado, nunca está perfectamente socializado" (1994: 77). La manera en la cual las diferencias de género se expresan por medio de configuraciones espaciales (dentro de la casa Kabyle, por ejemplo) puede ser descodificada como significados desde una perspectiva estructuralista, pero Bourdieu señala que la gente en realidad usa o produce esos espacios a través de movimientos corporales y de acciones para crear y reconstituir esos significados. Butler y Moore tienen aproximaciones muy diferentes, pero ambas se mueven hacia una unidad del significado y la acción corporalizada — aunque ellas tienden a verlas en relaciones de mutua constitución antes que ver cada una como inherente a la otra. El punto es que el énfasis en la materialidad del cuerpo es vital porque, obviamente, es a través de, o preferiblemente, en el cuerpo, como los humanos son activos o trabajan en el mundo: el cuerpo es "el fundamento existencial de la cultura," y una perspectiva que privilegia la corporalidad desafía el clásico dualismo mente/cuerpo, mental/

\footnotetext{
${ }^{6}$ La misma Butler ha sido acusada de menospreciar la materialidad del cuerpo; ver Ebert (1995). Sin embargo, la crítica de Ebert tiene como base la misma clase de distinción radical entre discurso y práctica material que deseo evitar.
} 
material, entre otros (Csordas, 1994). Una mirada completa de la corporalidad debe ver toda la actividad humana como corporalizada — pensar, hablar, bailar, "trabajar" (en el sentido usual).

\section{Cultura como objeto y como forma de vida}

La persistencia del dualismo material/simbólico en la antropología se debe en parte a los desarrollos de finales del siglo XX que nos alentaron - a académicos, no-académicos, e incluso a los activistas de los movimientos sociales - a restablecer la "cultura" y la "identidad cultural" como campos autónomos conformados por representaciones simbólicas. Estos desarrollos están íntimamente relacionados con la dominación política y la mercantilización económica.

Es reconocible que, para algunos que hasta hace poco consideraban la "cultura" una práctica relativamente naturalizada, sin conciencia, la "cultura" se ha convertido en una entidad objetivada, una cosa que ahora pueden desplegar y representar. La Cultura y la identidad cultural son cosas diferentes desde un punto de vista — la identidad es cultura "asumida concientemente" (Wagner, 1981: 34)—, pero coinciden cuando la cultura es objetivada como algo aproximado a los conceptos occidentales de propiedad. Wagner opone a los conceptos occidentales de creatividad humana que conducen a la "cultura" (como un conjunto de productos sean o no "refinados" o ordinarios), los conceptos melanesios de producción tanto de las personas como de las relaciones, asimismo como de las cosas (1981: 26-27). Tal oposición ya no parece tan simple, teniendo en cuenta que los pueblos no-occidentales también producen algo llamado "cultura" como parte de una conciencia sobre la identidad cultural en formas que han sido corrientes en occidente por largo tiempo (Stolcke, 1995; Wright, 1998).

Brown (1998: 197) señala de manera general que "la actual lucha por la soberanía política y cultural, a menudo induce a los activistas indígenas a hablar sobre la cultura como si esta fuera una cosa fija y corporalizada." Terry Turner $(1991,1992)$ ha descrito como los Kayapo en Brasil han tomado conciencia de tener "una cultura" en el contexto de la progresiva integración y dominación por parte del Estado nacional brasileño; el proceso que fue ayudado también por el proyecto de video Kayapo que él mismo ayudó a montar. Jackson (1995) cuenta una historia similar para los Tukanos en la Amazonía colombiana en el que se señala cómo al menos para los indígenas activistas que han recibido alguna formación, y que están comprometidos en una lucha por los derechos a la tierra, su cultura se convierte en objeto de discusión, análisis y representación en la interacción con la iglesia, los antropólogos, las agencias del Estado y también con otros activistas indígenas de los Andes. En Colombia, la cultura 
negra está también experimentando un proceso de objetivación en la medida en que surge como objeto del discurso del Estado, de antropólogos y activistas de organizaciones negras que luchan contra el racismo y en algunas regiones por reivindicaciones territoriales (Restrepo, 1997). Mientras en algún momento la cultura negra a duras penas existía como objeto de investigación y muchos antropólogos en Colombia y el exterior la consideraban simplemente como una variante menor de la cultura Iberoamericana, ahora hay un apasionado debate sobre la importancia de los Africanismos dentro de la cultura Afro-colombiana. La constitución de 1991 menciona de manera explícita "la identidad cultural" de las "comunidades negras" (Artículo Transitorio 55), y la Ley 70 de 1993 protege y promueve "la cultura de las comunidades negras" (República de Colombia 1996: 17, 35; ver Wade, 1995; Grueso, Rosero y Escobar, 1998).

El debate antropológico sobre este problema ha tendido a girar alrededor del esencialismo y del constructivismo. La objetivación obedece a un modelo de cultura entendida como una colección de cosas que pueden ser atesoradas, perdidas y redescubiertas, que pueden ser auténticas o inauténticas, inventadas o reales. Tal modelo viene en parte de las versiones post-boasianas de mitad del siglo XX, que ven la cultura como una unidad con características esenciales, versiones derivadas del nacionalismo romántico decimonónico (Friedman, 1994: 72; Pasquinelli, 1996; Williams, 1988: 89). En años recientes, esta visión de la cultura ha sido ampliamente de-construida por antropólogos, entre otros, quienes ahora tienden a ver la cultura como constantemente re-creada y reconstituida a través del discurso, más que como algo estable (Appadurai 1991; Friedman 1994: 74; Jackson, 1995; Wolf, 1982: capítulo 1). "La Cultura es contestataria, temporal, y emergente” (Clifford y Marcus, 1986: 19). Aquí, el énfasis está en la heterogeneidad y en la inestabilidad, y además en el rol del poder en la construcción de representaciones específicas de las culturas.

Pienso que el debate sobre el esencialismo y el constructivismo ha oscurecido otra dimensión significativa. ¿Qué significa exactamente la "cultura" que está siendo esencializada o de-construida? Bauman (1973) nos da un marco dentro del cual entender este proceso, enfocandose en un dualismo inherente en la experiencia humana: ser-un-objeto, a través del cual las personas experimentan dependencia y represión, y ser-un-sujeto, en el que las personas experimentan agencia y creatividad. La cultura como una facultad humana "es el perpetuo esfuerzo de sobrepasar estas dicotomías" (1973: 57). Para Bauman, la cultura es "la continua y permanente actividad estructurante (que) constituye el centro de la praxis humana, el modo en que los humanos son-en-el-mundo." La cultura consiste, dice Bauman, "del proceso de estructurar, junto con sus resultados objetivados - las estructuras hechas por los seres humanos" (1973: 56). 
Mi propio punto de vista es que los "resultados objetivados" a menudo son tomados como "la cultura" en sí misma.

Además, habría que anotar que este proceso generalmente ocurre en un contexto de hegemonía política y económica. Bauman extiende su argumento refiriéndose a una "sociedad alienada" (e.g. la capitalista) en la cual se ha producido una brecha entre lo privado y lo público. Aquí, el trabajo creativo de una persona, tendiente a la producción de control sobre de su vida, es forzado a valerse de la esfera pública (a menudo llamada "sociedad"), que es el lugar donde están localizados los mecanismos de control que se definen por el poder económico y político: "Al sacar de contexto el control del acto creativo y transplantarlo dentro de la esfera de lo trascendental (e.g. la esfera pública), el truncado producto del trabajo humano se presenta al sujeto como un acto completamente vaciado de su significado original e innato" (1973: 164). Asimismo, "en una sociedad alienada, [la] inalienable naturaleza de la cultura tiende a obliterarse u ocultarse" (1973: 173). Las últimas dos palabras indican que la cultura, como praxis, no desaparece en la sociedad alienada; queda encubierta. Esto significa que la lucha ocurre entre sujetos que tienen comparativamente poco control sobre sus vidas, pero que tratan de crear prácticas culturales que les darán sentido de control e independencia, y sujetos que controlan la esfera pública. El análisis de Bauman es demasiado pesimista en el sentido que descuida la lucha de los sujetos subordinados por invertir el producto de su trabajo con un sentido de control. Hasta las minorías oprimidas tienen que hacer uso de sus recursos en la esfera pública para alcanzar sus objetivos —o esas mismas minorías deben tratar de construir sus propios recursos privados aceptados como públicos.

No es este un tema que Bauman desarrolle, pero es importante comprender que esa no es simplemente una lucha de grupos minoritarios que ejercen una praxis cultural unificada contra concepciones alienantes de la cultura, producidas "desde arriba", que fragmentan sus propias nociones. Esta visión es demasiado romántica. Primero, cada uno, por obligación, vive en una tensión entre ejercer control y experimentar dependencia; todos en una sociedad capitalista enfrentan el encubrimiento de la inalienable naturaleza de la cultura. Pero, por su puesto, los grupos dominantes tienen un mayor acceso al locus del poder en la esfera pública desde donde pueden ejercer control sobre sus propias vidas y crear un sentido de ser-sujeto, asimismo como de ser-objeto. Segundo, las minorías con relativo poder están íntimamente involucradas en la fragmentación de su propia experiencia y en producir sus propias culturas como representaciones. Esto se debe a la necesidad de usar recursos localizados en la esfera pública, que incluyen definiciones dominantes no sólo de lo que constituye la "buena" cultura, sino además de lo que es la "cultura": la primera puede ser una definición 
ideológica, esto es, relativamente explícita y abierta al debate, mientras que la segunda probablemente sea más hegemónica, esto es, más tácita y sin opciones de contestar (ver Comaroff y Comaroff, 1992: 28-29). Las minorías ávidas de objetivar y controlar sus culturas, usualmente emprenden explícitamente este proceso en un escenario político de nivel nacional e internacional, dominado por una definición de la cultura como un conjunto de estructuras o representaciones objetivadas hechas por el hombre. Las agencias del Estado (y algunas Organizaciones no Gubernamentales -ONG's) a menudo se entusiasman al establecer relaciones con las culturas minoritarias que usan representaciones, centradas en expresiones estéticas y en actividades artísticas, ya que esto desvía cuestiones controvertidas sobre los recursos necesarios para desarrollar un sentido real de control por parte de las personas. Igualmente, cuando la objetivación de la cultura involucra también su mercantilización, el proceso de conversión en objetos de consumo generalmente se centra en prácticas que caen dentro (o son puestas dentro) de los campos de las expresiones estéticas y artísticas —artefactos, música, historias, etc. puesto que por definición es imposible "vender" una forma de vida. De esta forma, ciertos elementos de una cultura terminan representándola en su totalidad.

La Cultura entendida como productos artísticos, ha sido por siglos objetivada como mercancía en el mercado capitalista. Ahora, con la explosión de la mercantilización propiciada desde el periodo de post-guerra estamos presenciando la mercantilización no solo la cultura, sino de las identidades culturales - como recursos políticos y económicos. La mercantilización de la cultura y las identidades culturales es bastante clara cuando se la ve en relación con las industrias culturales. $^{7}$ Pero es aún más complicada cuando se la ve en relación con las identidades culturales de base. En esa misma línea, a menudo el énfasis se pone en cierto tipo de resistencia o al menos en la subversión a través de la apropiación y la resignificación. ${ }^{8}$ A pesar de todo, mientras esas identidades culturales son con frecuencia resistentes, ellas pueden ser generadas y trabajadas como objetos con la posibilidad de que circulen en circuitos de intercambio amplios (con potencia global); quizás en el libre mercado, pero más probable aún en redes del sector público y del voluntariado.

En el trabajo antropológico existe algunas veces cierta reticencia a ver las minorías oprimidas como productoras en sí mismas de identidades culturales como si se tratase de objetos que tiene una función mercantíl. Esta negativa proviene en parte de una tendencia a oponer el contra-culturalismo al capitalismo

\footnotetext{
${ }^{7}$ El tema fue trabajado por Adorno para la música—cf. Middleton 1990: cáp. 2; Urry (1990) lo trabajó en relación al turismo y Featherstone (1995) para la cultura global), lo que se ha analizado en profundidad.

${ }^{8}$ Ver Certau 1984; Scott 1985 y Taussig (1980). Sobre apropiaciones ver: Friedman, 1994: 105-9; Das, 1995; y Ota, 1997)
} 
moderno consumista. Pero, Campbell (1987) señala que tal consumismo está históricamente relacionado con una "afinidad electiva" (siguiendo a Weber) con movimientos románticos que desafiaban las convenciones sociales: "el romanticismo ha continuado trabajando en tal sentido, buscando sobreponerse a las fuerzas del tradicionalismo y tratar de proveer un renovado ímpetu a las dinámicas del consumismo", así como "un deseo de placer se convierte en una preocupación por ciertos ideales, e impulsos éticos 'degeneran’ en un mero narcisismo" (1987: 206, 216). La reticencia señalada arriba, obedece también a una tendencia de oponer lo local a lo global. Sin embargo, en Belice como lo muestra Wilk (1995), la "cultura local" es un producto global producido desde el principio en una plataforma global — lo mismo es aplicable a la cultura caribeña en general (Mintz, 1996). Si nos centramos en el nivel local de las identidades culturales — por ejemplo, aquellas construidas por los movimientos sociales - existe una gran tentación de examinarlas de algún modo resistiendo contra la predación del capitalismo global, o quizás apropiando estratégicamente elementos del capitalismo global. Pienso que es mejor que ver esas identidades como siendo construidas (aunque no desde cero) en plataformas globales y siendo ellas mismas producciones materiales que han sido trabajadas como mercancías, o al menos como objetos que forzosamente utilizan formas hegemónicas de mercantilización y objetivación de la cultura.

Esto no significa que tales identidades no puedan ejercer resistencia al capitalismo (o el Estado). Por el contrario, precisamente porque ellas han sido construidas de esa forma por medio del trabajo local, perfectamente pueden articular tal oposición. Como sostiene Sahlins (1993: 19), "para las preocupaciones de los pueblos indígenas, el sincretismo no es una contradicción de su culturalismo — ni de sus reclamos de autenticidad y autonomía_-, sino que es una condición sistemática. La oposición, no obstante, proviene no tanto de lo local, aún menos de la una identidad preformada "tradicional," sino más bien de la construcción dentro del contexto globalizado — que, por su puesto, incluye nociones de localidad y tradición como elementos de esa construcción.

La unidad de la actividad humana se divide en diferentes actores con diferentes historias, concepciones, y lugares en una jerarquía política. La oposición ocurre en la tensión entre la inalienabilidad de la cultura y su constante alienación tanto por grupos dominantes como por grupos subordinados, que en cualquier caso trabajan dicha tensión de diferentes maneras de acuerdo al poder que tienen para ejercer control sobre sus vidas y para dominar a otros. En este proceso, el dualismo simbólico/material que no ha sido todavía desterrado de nuestro propio análisis, es aparejado a esta tensión dinámica. Grueso, Rosero, y Escobar (1998), por ejemplo, indican que las diferentes prácticas que constituyen la 
identidad de la gente negra en la costa Pacífica de Colombia, involucran relaciones sociales en las que la selva, la comida, la gente, y las entidades supernaturales son manipuladas: no hay una distinción sencilla entre lo material y lo simbólico que pueda hacerse en este sentido. Con el rápido "desarrollo" de la región y la movilización y politización de la población negra, los procesos de objetivación y mercantilización de la cultura negra — asumidos por el estado, las ONG's, y los activistas negros - conduce a los activistas y observadores externos a considerar la cultura como un conjunto de representaciones. La cultura negra se convierte en una entidad que es usada en la lucha por obtener algún tipo de control local, pero que también está sujeta a poderosas fuerzas de cooptación "desde arriba". El problema con dicha construcción de la cultura negra es que se pone en juego dentro de un esquema bien establecido, manejado por los poderes dominantes, en el que la "cultura" está separada de la "política" y por ello mismo es entendida sólo desde una dimensión simbólica y no política. ${ }^{9}$ Si queremos contestar la división conservadora y tradicional entre la cultura y la política, entonces un camino para avanzar en esta agenda es cuestionar la profunda separación entre lo material y lo simbólico tal como se va sujetando a la objetivación de la cultura en una arena dominada por poderes hegemónicos.

En síntesis, mi argumento es que la actividad humana es indisolublemente material y simbólica al mismo tiempo. Las teorías sobre los movimientos sociales (junto con la teoría social en general) han luchado y desafiado los dualismos entre sentido y acción, significación y producción, material y simbólico, cultura y política. Sugiero que se puede avanzar en estos desafíos centrándose en la tensión entre la unidad de la actividad humana, en la cual no hay brechas entre "la cultura" y la política, y la fragmentación de la cultura y la identidad resultante de la reificación de "la cultura" en los circuitos políticos y mercantiles de las postrimerías del siglo XX. A menudo, la lucha política se trata de cómo arreglárselas sin que necesariamente se resuelva esa tensión. Para las minorías oprimidas se trata de cómo ganar un sentido de control, un sentido de subjetividad, en un mundo alienado en el que ellos tienen poco acceso al locus del poder. Para los antropólogos es útil para comprender la unidad de la actividad humana no como una modalidad pura y auténtica que lucha y que incluso puede llegar a borrar la alineación, sino más bien como una modalidad que existe en constante tensión con las formas objetivadas de cultura, una tensión que puede ser trabajada a través de vías más o menos opresivas. El trabajo corporalizado que la gente emprende para crear un sentido de control sobre sus vidas, inevitablemente los ubica en una relación potencial con otros

\footnotetext{
${ }^{9}$ Cf. Campbell (1987: 216), quien anota que la búsqueda de placer en el consumismo puede generar idealismo, en el contexto de "una perspectiva romántica más general", mientras que también se puede convertir en simple materia prima para la industria del entretenimiento cuando "prevalecen las creencias materialistas y utilitarias".
} 
que, en similares posiciones de clase, están haciendo las mismas cosas. Las diferencias culturales que se hacen explicitas cuando la cultura se entiende como representaciones tal vez pueden pasar a un segundo plano al entender la cultura, en los términos de Bauman, como un intento por sobrepasar el dualismo entre ser-un-objeto y ser-un-sujeto.

En las líneas siguientes muestro cómo la cultura es usada, trabajada y manipulada por diferentes grupos en la ciudad de Cali. Todos los grupos involucrados -el gobierno local, las ONG's, un grupo de rap comunitarioproducen la cultura como un conjunto de representaciones, pero para el grupo de rap (foco del estudio de caso) la representación es un intento por ganar control sobre sus vidas, como habitantes negros y pobres de un barrio marginal. En este proyecto la cultura se considera como una forma de vida, pero como tal existe en una permanente tensión con la cultura como representación. Cali no es una excepción en este sentido: los procesos que describo son ampliamente conocidos, y muchos otros ejemplos podría haber sido escogidos. La especificidad del caso de Cali está dada por el lugar de las poblaciones negras en el contexto histórico de Colombia (y América Latina), por el surgimiento en el país del movimiento social negro junto con el nacionalismo multicultural, por el reciente crecimiento de la población negra joven en Cali, y por la relación de los jóvenes negros en Cali con el reggae y el rap.

\section{Grupos de rap negros en Cali}

Debido a la innegable ambigüedad sobre el significado de lo "negro", determinar con exactitud la población negra de Colombia no es una tarea fácil. No obstante, hay áreas del país donde los Afrodescendientes están fuertemente concentrados. Una de esas áreas es la costa Pacífica, área selvática y con poco desarrollo infraestructural, habitada por varios grupos indígenas y en su gran mayoría por descendientes de esclavos africanos llevados allí, durante la colonia, para trabajar en las minas de oro (Wade, 1993; Whitten, 1986). Esta área está experimentando actualmente un rápido cambio social y económico dirigido principalmente por fuerzas externas provenientes de diferentes partes del país. Esto ha resultado en un incremento de la migración, alguna de ella hacía la ciudad de Cali que se encuentra en una región que ha tenido y tiene una importante población negra, originalmente empleada en la minería y la agricultura (Taussig, 1980).

Los negros rurales en la región del Pacífico generalmente se refieren a sí mismos como libres o morenos, más que como negros o afrocolombianos. No obstante, no ubican el término libre dentro de una estricta narrativa sobre la esclavitud, ni tampoco existe una memoria colectiva que haga referencia a los 
orígenes africanos (Losonczy, 1997: 354; Restrepo, 1997). Sólo recientemente, y en especial en círculos politizados, algunas personas están comenzando a hablar de negros o de Afro-colombianos. En Cali, y en otros ambientes urbanos, el término negro es más común, aunque hay que anotar que en ciertos contextos, dada la carga simbólica del discurso colonial y nacionalista que ha desvalorizado la negritud y realzado lo blanco, este término puede ser percibido como un insulto y ser reemplazado por el eufemismo moreno (Wade, 1998; Whitten y Torres, 1998). Asimismo, influenciado por los movimientos sociales negros en Estado Unidos, ha aparecido desde 1960 un movimiento social negro localizado en áreas urbanas y liderado por negros con escolaridad (Wade, 1995) que ha reivindicado el uso de negro y algunas veces de gente negra como términos de auto-referencia. Desde sus comienzos este movimiento también recibió el apoyo de un pequeño grupo de académicos quienes han estudiado la historia de las comunidades negras, a menudo con la visión de redescubrir huellas de africanía (e.g., Arocha, 1996; Friedemann y Aroca, 1986; Friedemann, 1993). Esto ha animado el uso, cada vez más, del término afrocolombiano.

Recientemente, los conceptos de comunidad negra, cultura negra y negros como un "grupo étnico", han sido consagrados en la legislación colombiana. La constitución de 1991 declara que Colombia es una nación pluriétnica y multicultural e introduce artículos que protegen los derechos de los indígenas y los negros a la tierra, a la "etnoeducación," y a la libertad en contra de la discriminación racial (Arocha, 1991; Wade, 1995). En 1993 se promulgó la Ley 70 que definía, entre otras cosas, los procedimientos para titular la tierra de las "comunidades negras" en la región del Pacífico (Grueso, Rosero y Escobar, 1998). Asimismo, se configuró una oficina de Asuntos de Comunidades Negras como parte del Ministerio del Interior, y se proporcionó dos curules en el congreso para las comunidades negras. Estos cambios han promovido la formación de grupos que reivindican una identidad negra o Afrocolombiana, incluyendo grupos comunitarios que buscan títulos colectivos de tierras en el Pacífico y numerosas ONG's, que van desde cooperativas para la producción, pasando por organizaciones para el desarrollo y la educación, hasta grupos de danza y música. Los partidos políticos formales también se han adaptado a este proceso. Al mismo tiempo, las iniciativas del Estado han alcanzado niveles locales. Por ejemplo, en 1996, la División de Asuntos Negros fue creada como parte de la administración de Cali.

Cali es la tercera ciudad de Colombia, un gran centro industrial localizado en medio de una rica, y altamente capitalizada región cañera. Cali tiene la población negra urbana más grande del país (Urrea, 1997). Gran parte de esta población, compuesta de inmigrantes, vive en el Distrito de Aguablanca, una vasta área 
con habitantes de bajos ingresos que surgió aproximadamente desde 1970. En términos generales la población de Aguablanca es más joven, más negra, más pobre, más vulnerable desde el punto de vista de la salud y más afligida por la violencia que cualquier otra parte de la ciudad. En términos de densidad en algunos barrios del distrito de Aguablanca, los inmigrantes negros y los negros nacidos en él forman una evidente mayoría; en otros la población negra es minoritaria. Por fuera de Aguablanca también se encuentra población negra que incluye empleadas de servicio en casas de ricos, negros mejor acomodados, y negros pobres que viven en otras áreas de bajos ingresos en la ciudad (Urrea, 1997).

Mi investigación se centró en la intersección entre la reivindicación de la cultura y la identidad negra, y la práctica de la danza y la música. Deseaba conocer qué vínculos e interacciones tenían las organizaciones negras, centradas en la identidad negra como un proyecto básicamente político, con grupos de jóvenes negros que tenían un perfil más cercano a la música y la danza. De hecho, consideré tres tipos de actores, todos trabajando en el campo de la promoción de la "cultura" (negra), entendida aquí generalmente como una expresión estética y no como un estilo de vida en todos sus aspectos: a) El gobierno local y regional (principalmente la Alcaldía, pero también la Gobernación del Departamento del Valle del Cauca); b) ONG's de la ciudad y del país, incluyendo las fundaciones de bienestar gerenciadas por jesuitas, movimientos políticos electorales afro, movimientos políticos afro no-electorales, organizaciones pequeñas de investigación, promotores de "eventos culturales", y un par de bandas; c) Grupos comunitarios y agrupaciones particulares que incluyen bandas, grupos de danza, ONG's negras, y otras organizaciones.

Para examinar esos diferentes grupos, sus agendas, y la manera cómo trabajan con la cultura, me centraré inicialmente en uno de los grupos del nivel comunitario, un grupo de rap llamado Ashanty, ${ }^{10}$ que también se autodenomina "Asociación etno-educacional y cultural". La organización estaba localizada en Charco Azul, uno de los asentamientos más pobres, con las tasas más bajas de ingresos en Aguablanca, una de las áreas de invasión menos consolidada y con un porcentaje muy alto de población negra. ${ }^{11}$ Miraré primero el grupo mismo para analizar cómo lo veían el Estado y las ONG’s de alto nivel.

${ }^{10}$ Uso el nombre del grupo porque (a) ya es de dominio público que alude a un grupo de rap y una asociación etno-cultural, (b) también se conoce a nivel público entre los académicos (ver nota II) y (c) además cuando se les preguntó a los miembros del grupo, ellos expresaron el deseo que se usara su nombre real en este artículo.

${ }^{11}$ Los datos del censo, aunque son mediciones útiles, no permiten arrojar un estimado para el nivel del barrio, en cualquier caso, tales datos revelarían únicamente los lugares de nacimiento de los individuos (y por lo tanto el origen en "áreas negras" tales como la región Pacífica). Sin embargo, estimativos informales indican que tal vez $60-70 \%$ de la población local es negra. 


\section{El Grupo de rap}

En 1997 cuando encontré por primera vez el grupo había tres miembros centrales a quienes llamaré F, J y R. Como adolescentes, a mediados de los ochenta, los tres habían participado en las típicas actividades y proyectos de organización comunitaria en el marco de eventos anuales como la Navidad. Esto había aportado las bases preliminares de un grupo informal (Nueva Generación) conformado por jóvenes que se juntaban para charlar. El centro comunitario local (que se construyó con dineros del municipio y fondos nacionales e internacionales de ONG's, además del trabajo de la comunidad) se abrió para apoyar esta clase de iniciativa, pero el grupo permaneció relativamente autónomo y empezó a practicar canto y danza, usando instrumentos rudimentarios como cajas y tarros. Fue un proceso autodidacta; ninguno tenía experiencia o entrenamiento musical. Aunque no existía ningún tipo de organización conjunta surgieron, en este periodo, aproximadamente veinte (20) grupos de gente joven. Muchos se desintegraron, otros permanecieron y algunos líderes se consolidaron. Uno de ellos fue un grupo de mujeres, otro enfrentaba los problemas relacionados con drogadicción, pero la mayoría se centraba en la música y en la danza, en especial en el currulao, ${ }^{12}$ reggae y rap, siguiendo estilos estadounidenses y jamaiquinos que llegaron a Cali a través de Buenaventura. Dada la carencia de instrumentos y entrenamiento musical, la mayoría de la música fue a capella o acompañada únicamente por pistas de música comercial puesta en grabadoras.

En este contexto, Ashanty surgió en 1992 como un grupo de reggae y rap que paulatinamente había ido incorporando una agenda social y política. Miembros del grupo participaron en sesiones de rap espontáneo que se realizaban los domingos cuando una de las principales calles de la ciudad se cerraba con fines recreativos (Ciclovía). También asistían regularmente al bar Nuestra Herencia, fundado por Mario "Rasta" Campaz en 1989 como un sitio de reggae y salsa ${ }^{13}$ (Para 1997 los raperos de la Ciclovía y de Nuestra Herencia habían desaparecido, aunque en 1998 otra escena de la Ciclovía había re-surgido y los Ashanty habían organizado, por iniciativa propia, otro bar con un nombre similar). Los miembros de Ashanty fueron ávidos consumidores de las películas de Spike Lee, especialmente la de Malcom X de 1992, y participaban en los talleres ofrecidos por el movimiento de los Derechos de los Negros, Cimarrón, ${ }^{14}$ recogiendo información sobre líderes afro como Martin Luther King y Nelson Mandela,

\footnotetext{
${ }^{12}$ En la región Pacífica, el currulao es un estilo de gran influencia africana, los grupos lo tocan con marimba y varios tipos de tambores (ver Whitten, 1986; List, 1980).

${ }^{13}$ Sobre Ashanty y Mario Campaz, ver también Waxer (1997) y Ulloa Sanmiguel (1995). Campaz ha creado una página web que también ofrece alguna información: http: \\home.fia.net $\backslash \sim$ rasmario

${ }^{14}$ Movimiento Nacional para los Derechos Humanos de las Comunidades Negras de Colombia (Nota del Editor).
} 
asimismo aprendiendo cómo organizar sus propios talleres y cómo diseñar sus proyectos (ver Wade, 1995). Las actividades de Ashanty eran variadas, en 1996 organizaron un concierto de rap gratuito que puso en escena a diecisiete (17) grupos de rap de toda la ciudad y que fue la culminación de una serie de talleres en varios temas, por ejemplo, técnicas vocales o la historia de la "cultura bip-hop." La empresa había sido financiada por el bar Nuestra Herencia, la ONG Plan Internacional, Desepaz ${ }^{15}$ (una agencia local del gobierno para la promoción del desarrollo), un grupo de teatro de la localidad y la Arquidiócesis (que atendió gran parte de la organización infraestructural). Durante el periodo de la investigación, se organizó un segundo concierto que no contó con los talleres precedentes y fue apresurado, caótico, y menos exitoso en atraer público.

¿Cómo trabajaron los miembros de Ashanty la "cultura" y la identidad? De un lado, vivieron su cultura como estilo de vida de una manera unificada (que no es lo mismo que decir que formara un todo unificado). De otro, estuvieron constantemente involucrados en producir representaciones de su cultura como un objeto, un conjunto de símbolos de sus vidas y las vidas de otros. Sería equivocado ver esta tensión como una simple oposición entre una unidad local "auténtica" y una sociedad fragmentada y alienada, porque de hecho la tensión existía dentro del grupo y su localidad como parte de la experiencia diaria como miembros de una sociedad capitalista y alienada. La cultura y la identidad negra fueron preponderantes para ellos, aunque también se enfocaron en problemas generales (pobreza, educación, violencia, drogas) que afectaban su barrio. El problema del racismo fue central y no reductible a un problema de clase. Como decía uno de ellos, "Una persona no-negra se coloca un plante bien clean [un traje elegante] y se va para su Sexta y pasa. Un negro se coloca el plante mejor del mundo y sigue el mismo problema [el rechazo]". Para ellos la iglesia y muchas ONG's con las que interactuaban no admitían que había un problema de racismo. Así, para los Ashanty la cultura negra no era simplemente una expresión estética y un estilo, sino además la experiencia del racismo.

Este énfasis fue evidente en su promoción del rap, de reggae, y del ragamuffin, como parte de lo que ellos llamaban "la cultura bip-bop." Dos de ellos tenían trenzas rasta y a menudo se vestían con los colores rasta (verde, rojo y amarillo). El rap y el reggae, especialmente el ragamuffin, eran partes vitales de su mundo y de su propia imagen. Uno de ellos decía que esto había sido una revelación proveniente de los videos de rap: "ver una persona negra diciéndole a los demás que lo respeten; y ver que era un negro bien, no sólo que tenga unos plantes bien, (bien vestido), sino un negro bien! Pues, eso era lo que uno necesitaba ver. La parte musical, el ritmo, era importante, pero mucho más lo que uno podía

${ }^{15}$ Consejería para el Desarrollo, la Seguridad y la Paz. 
ver." Otro agregaba, "Y el ritmo es agresivo, y uno se identifica con eso. Ese ritmo, ese golpe, eso es lo que uno vive; está golpeadito, entonces ese golpe le entre a uno y no sólo por los oídos, sino además a través de los poros, porque es algo uno traspiras."

Su visión de la identidad negra fue vivida y objetivada en relación con un afrocentrismo parecido en algunos aspectos al encontrado en los EEUU. Escribieron una propuesta para una serie de talleres titulados "Derechos de las comunidades Afrocolombianas" que trataba de temas como "Nuestros orígenes africanos," "Orígenes de los ritmos africanos," y "La contribución de los Negros a la construcción de Colombia." Al discutir el esquema para los talleres sobre los Orígenes Africanos, uno de los miembros del grupo, N, propuso energéticamente la idea de que todo había nacido en África. La humanidad se había originado allá, de ahí que toda la cultura hubiera sido originada en África, incluyendo los ritmos musicales. Mi comentario sobre la amplitud de esa mirada histórica, que ignoraba los largos procesos de diversificación cultural, produjo poco impacto en su punto de vista. Para él, el reggae, el rap, el currulao, el blues y la salsa — sólo por mencionar los más obvios_ eran todos básicamente africanos, conectados por un hilo histórico continuo.

En resumen, los miembros de Ashanty "africanizaron” su cultura con una clase de africanismo genérico globalizado y mercantilizado, disponible para ellos a través circuitos globales de intercambio. El punto de convergencia para los Ashanty era la peluquería, localizada cerca del barrio y administrada por dos negros que no vivían allá. Los símbolos en las paredes incluían estrellas de reggae (Bob Marley y Lucky Dube), raperos negros estadounidenses (Public Enemy), y estrellas negras del básquet (Michael Jordan). Uno de los miembros de Ashanty que trabajó cortando pelo, también colaboró decorando el exterior del lugar (el muro), pintando el nombre del local "Peluquería África" con los colores rasta. Antes había un mapa de África pintado a mano. Aquí, la identidad se construía en una continuidad percibida desde la resistencia negra en las Américas y el Caribe, remontándose incluso a África. Las objetivaciones de los miembros de Ashanty de la cultura del hip-hop, contenida, por ejemplo, en los proyectos para los talleres presentados a instituciones financiadoras, se construyeron en relación a las poderosas representaciones globales de la negritud, formadas por modas de consumo y por los criterios dominantes sobre lo que se consideraban proyectos aceptables. Ellos estaban recurriendo a elementos localizadas en la esfera pública y definidos por formas hegemónicas, con el fin de lograr un mayor control sobre sus propias vidas.

Pero esto no fue un collage hecho de todo y nada al mismo tiempo: únicamente algunas cosas disponibles en los circuitos globalizados fueron 
fácilmente accesibles a los Ashanty y, lo más importantes, únicamente algunas cosas fueron consideradas como históricamente relevantes para su situación local y personal, para su compromiso práctico con su mundo. La relación entre vivir una identidad negra en un barrio en Cali y representarla para amplios circuitos ayudó a definir tanto la representación como la identidad vivida. La naturaleza espontánea del rap y sus bajos requerimientos tecnológicos lo hacían accesible para ellos y otros jóvenes en condiciones similares. La identificación del rap - y el reggae - con la autonomía y la protesta negra, al igual que con la juventud, vehiculaban sus ideas sobre la injusticia y la inequidad que ellos vivían. Las continuidades de las que $\mathrm{N}$ hablaba en su visión afrocéntrica de la historia estaban relacionadas con continuidades personales. Para él, la salsa, el reggae y el rap estaban todos conectados con su propia vida. Hablando de experiencias tempranas con la música, él mencionada la importancia de "esos ritmos, esos buenos ritmos siempre han marcado mis cosas". El sentido representativo de esa música con su perfil orientado a los jóvenes, la rebelión, y relacionado a artistas negros era inseparable para él de la experiencia corporalizada de escucharlos y bailarlos. Su pelo al estilo rasta, que se dejó crecer a inicios de 1990, es un buen ejemplo de un forma de compromiso corporal que es material y simbólico a la vez, un proceso de trabajo — que iba de un estilo de cabello Afro, pasando por estilo un "relajado" a lo Michel Jackson a finales de los años 80, llegando a la adición de pequeñas trenzas - en que los circuitos trasnacionales de representación configuraban un proyecto social de orden personal y colectivo de vivir la cultura como una forma de vida.

Claramente los miembros de Ashanty estaban "construyendo" una identidad cultural como una realidad vivida, una forma de ser y experimentar el mundo. Pero, en el mismo sentido sugerido por la metáfora de la construcción, ellos estaban también produciendo algo que podía ser representado, esbozado en propuestas de proyectos para agencias financiadoras, y presentado a otros jóvenes en talleres. Había un constante movimiento entre estas dos modalidades de cultura, ambas alimentadas por elementos transnacionales, provenientes de los medios masivos, de los circuitos de consumo y ambas objetivaciones motivadas a conquistar recursos en la esfera pública. La experiencia corporal de ser hombres negros y pobres en Cali, alimentó en cada uno de ellos una lucha por ganar control y subjetividad, y hacer de esa subjetividad misma (e.g. la africanidad o la cultura hip-hop) un recurso público en la sociedad colombiana antes que una aberración privada.

Una característica que me llevó a pasar tiempo con los Ashanty (y con otros grupos en los barrios de Aguablanca) fue el duro trabajo invertido en la construcción de una identidad. Este trabajo involucraba hablar, pensar, escribir 
proyectos, gestionarlos en el gobierno local, la Iglesia, las ONG's. Asimismo, organizar eventos, cantar, danzar, escribir canciones, y sudar el ritmo por los poros. Todas esas actividades se interconectaban hasta alcanzar una experiencia unitaria en la cual lo simbólico y lo material eran imposibles de separar. Todas eran culturales por definición; todas eran necesariamente políticas porque formaban parte de una forma de vivir bajo la sombra de la pobreza, el racismo, y la violencia. Al mismo tiempo, también estaban en parte encaminados a producir representaciones de esta unidad de experiencia que necesariamente se debían descorporalizar y deslocalizar dicha unidad para lograr los efectos requeridos en la oficina de la Alcaldía y las ONG’s.

Los miembros de Ashanty invirtieron mucho tiempo tocando puertas en varias agencias gubernamentales, la iglesia, y ONG's para lograr financiación para los proyectos que ellos escribían en un computador del hospital local. Trabajaban en lo que un funcionario de una ONG llamó el "la cultura del proyecto", es decir, un circuito en el que cada grupo tenía que conocer cómo preparar un proyecto que pudiera ser presentado a ONG's, secretarías del gobierno local, y de académicos visitantes. A nivel muy local este trabajo significó reunir todos los grupos de rap y danza del barrio, para hablar sobre la cultura hip-hop y también para tratar de organizar talleres que condujeron al concierto de rap de 1997. Esos intentos demandaron un gran esfuerzo por parte del grupo: se notificó a cada uno, se consiguieron espacios como los centros comunitarios, se cercioraron de que no faltara nadie a la convocatoria, se consiguió una máquina de video y una grabadora. Yo tuve la oportunidad de asistir a varios encuentros poco productivos en los que tres miembros de Ashanty recriminaban a los otros: "ustedes también tienen que trabajar". Ellos lo que buscaban precisamente era hacer de la cultura hip-hop una parte más integral de la realidad del día a día de los demás. Todos esos jóvenes también rapeaban y danzaban en cierto sentido, pero tenían que estar comprometidos en la organización de esas actividades. Esos encuentros fueron, desde un punto de vista, "puramente simbólicos" — la mayoría de las veces fallaban en lograr algo concreto. Pero, desde otro punto de vista, movilizaban un compromiso activo — trabajo- que tenía múltiples efectos. Los salones se llenaban lentamente con cada persona o pequeño grupo que llegaba. Se intercambiaban apretones de manos, se hacían conexiones, las personas se localizaban así mismas en relación con los otros y con el barrio como un todo en la medida en que estaban en el centro comunitario.

Mientras estuve en Cali, los Ashanty organizaron una suerte de kermés. Ello consistió en poner un equipo de sonido (de su propiedad) en una cancha de fútbol, comprar en consignación canastas de cerveza y gaseosas a un distribuidor mayorista local, y organizar un torneo de fútbol de medio día y una rumba 
por la noche. Este evento atrajo una multitud de hombres y mujeres negros, y fue, en un sentido importante, una declaratoria de identidad: "Esto es lo que somos (jóvenes negros), esta es la música que nos gusta (rap, reggae y salsa)". Fue la creación pública de un espacio de jóvenes negros en una ciudad que se percibe así misma como blanca (blanqueada). Pero, como muchos geógrafos han señalado, la creación de un lugar es algo que requiere inversión, y esta inversión viene de vivir — ser, trabajar - en un lugar. ${ }^{16}$ Este "evento cultural" del barrio no sólo representó la cultura bipp-hop, sino que, además, se convirtió en esa cultura, involucrando actividades diferentes que evocaron sentidos y fueron al mismo tiempo materiales. El trabajo infraestructural consistió en vender cerveza, poner música, y hacer todas las cosas necesarias para poner en marcha el evento: negociar con los distribuidores de licores, buscar hielo para enfriar la cerveza, traer el equipo de sonido de otro barrio (acción que amenazó torpedear el plan hasta que ofrecí pagar el taxi para traerlo). Cada tarea posibilitó, a través de la evocación y la promulgación, las relaciones económicas y de poder existentes entre los organizadores y los distribuidores de licores, entre ellos y otros colaboradores en el barrio, entre ellos y el etnógrafo. Al igual que los encuentros en el centro comunitario, el evento permitió juntar a las personas - posicionándolas en relación unos con otros en el barrio contagiándolos de la cultura hip-hop a través de un modo activamente corporalizado de deporte y danza, que requería no solamente esfuerzo físico sino preparación física (vestirse, maquillarse etc.). Desde el punto de vista de los Ashanty, el evento fue en ese momento una expresión de identidad, pero también una forma organizativa. Dada la dificultad para convocar a los más jóvenes del barrio dentro de los talleres, vieron la fiesta como un evento clave para atraer la gente y mostrarles qué se podía hacer. Mi argumento es que la división entre lo material y lo simbólico, o la existencia de una brecha entre la cultura y la política, no aplica cuando vemos el evento como parte de una cultura hip-hop vivida.

Sin embargo, la posibilidad de que el evento fuera una pieza de cultura descorporalizada y deslocalizada estaba presente. Primero, los medios usados para producir el evento hacían parte de la cultura masiva de consumo - la competencia deportiva, la música comercial, los raperos con trenzas rasta exhortando al público a comprar cerveza en un estilo fácilmente reconocible de los comerciales de los medios masivos de comunicación-y sin duda fueron entendidos de esa manera por parte de muchos de los participantes. Segundo,

${ }^{16}$ Geógrafos Marxistas (por ejemplo Harvey, 1982; Massey, 1984) han hecho énfasis en la acumulación sucesiva de capas de infraestructura - pero también de relaciones sociales- lo que permite y obliga al cambio. Geógrafos y arqueólogos fenomenólogos (por ejemplo, Tuan, 1997 y Tilley, 1994) han hecho énfasis sobre el compromiso humano con el significado del lugar en una relación dinámica con el entorno natural. 
este tipo de evento había sido objeto de varias solicitudes de fondos no exitosas a la Alcaldía por parte de los Ashanty. Tercero, $\mathrm{N}$ me dijo después del evento que se comentaba que los Ashanty habían ganado gran cantidad de dinero por el evento, asumiendo que todo lo que implicó la jornada había sido sólo por lucrarse. En realidad el evento buscaba conseguir algunos fondos para sostener las gestiones de los Ashanty, sin embargo, esto fue objeto de diferentes lecturas: una simple venta de cultura mercantilizada o el desenvolvimiento de todo un proyecto cultural.

La organización de un gran concierto de rap en la ciudad, que tuvo lugar el 17 de Agosto de 1997, ilustró la naturaleza unificada de lo material y lo simbólico en la identidad cultural de los Ashanty, más ampliamente, en la cultura hip-hop que vivían; pero también significo la posibilidad de desagregar dicha unidad. Hubo menos apoyo para el concierto que en el año anterior; aunque existió alguna ayuda de un periódico local (en publicidad), de una compañía de cerveza, de un miembro del Movimiento Nacional de Comunidades Negras, y algo de mi parte, la arquidiócesis fue el principal contribuyente. Al final el evento se llevo a cabo con un sistema de sonido más pequeño que el prometido, la asistencia fue baja (mucho menos de 1000 personas), y el recaudo no fue bueno. El evento fue, como el día en de "Música deporte y cerveza", una forma de unidad: el trabajo de organización, la obtención de dinero, cantar, bailar, vestirse y peinarse al estilo hip-hop (tanto los artistas como los asistentes) y unirse en lugar fue simultáneamente una actividad material y simbólica. Sin embargo, como evidencia de que la unidad de la actividad humana está en constante tensión con su fragmentación, el evento desplegó por supuesto toda la parafernalia de una venta estandarizada y mercantilizada de "cultura popular" que generó un malestar y conflicto alrededor del dinero. En el último acto de dos negros raperos, el equipo de sonido se averió. El suceso concluyo con recriminaciones por parte de los raperos a los Ashanty y acusaciones sobre el mal manejo del dinero que debería haber sido redistribuido entre todos los participantes. La unidad de la actividad fue objeto de diferentes lecturas que unían o separaban lo material y lo simbólico: desde un punto de vista, la cultura hiph-hop se promocionó; desde otro punto de vista, los Ashanty estaban explotando a sus compañeros.

Bajo esta luz, el comentario de F después del concierto de rap fue revelador. El señaló que por primera vez en Cali, la gente había pagado por ver rap en vivo (el año anterior la entrada había sido gratis). Esto, para él, fue más que un índice de posibilidades comerciales; fue una expresión de la unidad de la actividad humana y de la identidad Ashanty. La gente había pagado por una dosis de identidad cultural: habían usado recursos propios (o de sus padres), duramente ganados, para participar en la cultura hip-hop como una totalidad antes 
que comprar un producto. Desde su visión, esto sólo hacía del evento un éxito. "Pagar por" tal vez para él, sea similar a "trabajar por". Para otros esto tal vez simplemente signifique exactamente la mercantilización —y, en realidad, para F ese significado existía en una tensión constante con su alternativa.

Esta tensión fue visible en mis propias relaciones con los Ashanty. Ellos eran conscientes de estar expuestos a ser utilizados por los investigadores cuyos esfuerzos estaban más encaminados hacía el mercado del conocimiento y el desarrollo de sus carreras académicas en. Además, esto fue importante para ellos y para mí, en el sentido de que hubo cierta reciprocidad en nuestra relación. Me pidieron información que pudiera alimentar su lucha por la identidad cultural, y junto con un colega, Fernando Urrea (Fernando ha estado dirigiendo una investigación prolongada sobre los negros inmigrantes a Cali), llevamos a cabo un taller con los Ashanty en el que Fernando presentó algunos resultados del proyecto y yo discutí con ellos sobre racismo, clase social, e identidad negra. Yo prometí enviarles información pertinente desde el Reino Unido. Además hice una donación significativa para su concierto de rap, y esto desencadenó un momento interesante. El apretón de manos había sido siempre una interacción confusa en nuestros encuentros, uno que siempre ponía en evidencia mi no pertenencia al grupo. Entre los raperos un típico apretón de manos era el contacto de puños, nudillos con nudillos. Cuando me tocaba a mí, casi siempre me daban un apretón "normal". Otros raperos, que no sabían quién era yo o lo que hacía, me ofrecían su puño. Yo, esperando el apretón normal, les ofrecía la palma abierta; inmediatamente mientras yo cerraba el puño ellos abrían la palma de la mano. Sin embargo, después de haber contribuido con dinero, uno de los Ashanty deliberadamente me ofreció su puño cerrado diciendo "Ya entraste con los duros". Yo había contribuido a su proyecto: esa contribución podría interpretarse simplemente como algo material, una mercancía, quizás como una forma de comprar mi entrada a los datos que necesitaba para mi proyecto, o podría ser interpretada como una forma de participación en una forma de vida, una forma de cooperar aunque fuera momentáneamente en los bordes de su identidad cultural. La ironía del gesto y el comentario realzaban la ambigüedad de mi acción.

Una segunda característica que me impulsó a trabajar con los Ashanty, a pesar de la preocupación evidente del grupo por la identidad negra, fue la forma como los asuntos relacionados con la problemática de clase aparecían continuamente en la agenda. Los Ashanty tenían la reputación de ser "racistas" entre otros negros jóvenes con los que hablé — miembros de otras agrupaciones musicales, trabajadores de ONG's, etc.-, es decir, se les recriminaba por hacer demasiado hincapié en la reivindicación de la negritud y las raíces africanas; por 
ser tan "sensibles" sobre la raza. Sin embargo, tanto en su discurso como en sus relaciones sociales, había un fuerte interés por los asuntos de clase. Mientras que en su repertorio de canciones figuraba una que se llamaba "Negro 100\%" que afirmaba la identidad negra y la solidaridad, la letra de la canción "Dispara" era una respuesta sobre la explotación y el maltrato en el trabajo, asimismo como sobre la pobreza y la violencia. Gran parte del contenido era sobre la carencia de servicios en el barrio — la falta de presencia del Estado, de educación, y salud - así como de la violencia que sufrían de mano de las autoridades. El barrio tenía una población mayoritariamente negra, pero también tenía una minoría significativa de no-negros. Además de esto, su discurso cobijaba toda Aguablanca, no sólo su propio barrio. De esta forma, sus discursos se movían entre la problemática de la identidad racial y la de clase.

Desde la perspectiva elaborada más arriba, esto es perfectamente lógico. El racismo y los problemas generales de pobreza y violencia se experimentaron de manera unificada, no separable en problemas de "raza" y "clase" o identidad y recursos materiales. Esto trae a colación la famosa frase de Hall "la raza es la manera en la cual la "clase" es vivida" (1980: 340). Pienso que esto es válido en un sentido general, pero sugiere que la raza es (la superficie) la forma, mientras que la clase es (el sustrato) la sustancia. Yo quisiera sugerir que la experiencia es vivida de forma unificada, pero en constante tensión con las objetivaciones que fragmentan la experiencia en los componentes de raza y clase. Esto se puede reflejar en las propias experiencias de la gente dentro de un contexto social particular (jerarquizado) o por investigadores luchando con problemáticas teóricas (dos conjuntos de actores en una relación reflexiva). En el caso de los Ashanty, el contexto total fue la Colombia urbana, donde no existe una estricta segregación racial como la que se puede encontrar en otras áreas de Afro-latino América. Un contexto donde se presenta, lo que he llamado en otro lugar como la coexistencia de lo negro y el mestizaje, de la discriminación y la asimilación (Wade, 1993). Esto milita contra las definiciones de la experiencia entendida exclusivamente desde el punto de vista de las identidades raciales.

En un nivel más específico, el problema de juntar una noción de identidad cultural, una asociación etno-educativa y cultural, o una presentación de rap, llevó a los miembros de Ashanty a otros raperos quienes estuvieron haciendo la misma cosa y quienes podrían ser negros o no negros pero igual poco relacionados con una identidad Afro o negra. Por ejemplo, el Cartel Cali Rap, una unión de grupos poco cohesionados, cuyos miembros más prominentes eran un negro y un mestizo, usaban toda la parafernalia y estilo del rap estadounidense, sin embargo, el foco de su letra y preocupaciones eran los problemas sociales causados por los bajos ingresos en Cali: violencia, desempleo, etc. Varios grupos del Cartel tocaron 
en el concierto organizado por Ashanty y fueron activos en las preparaciones previas a su realización. El proyecto de Ashanty no se limitó a sus miembros inmediatos, sino que se extendió a otros vistos como iguales (estas "similitudes" construidas de manera flexible, podían anular diferencias; como por ejemplo las condiciones similares de pobreza podrían anular las diferencias entre negro y no-negro; la similitud en lo negro podía asimismo anular las diferencia de genero $^{17} \mathrm{o}$, más importante, las adscripciones a la cultura bip-bop podían anular una variedad de diferencias).

En síntesis, aunque los miembros de Ashanty movilizaban un esencialismo al construir su identidad cultural, fue un esencialismo que en la práctica no fue excluyente, porque su insistencia en el racismo y en lo negro fue constantemente combinada con asuntos de clase a los que se enfrentan en la experiencia vivida de su identidad y que los llevó a compartir causas comunes con otros. Un énfasis en los aspectos de representación de su identidad, los desarraigó de su experiencia del día a día, poniendo en un primer plano el afro-centrismo y la diferencia; un énfasis en la unidad de la vida de sus identidades puso en primer plano sus experiencias comunes. Este énfasis en el impacto práctico y en el contexto de las construcciones esencialistas (vistas como estratégicas o no) ayuda a evitar el impasse creado por la automática condena del esencialismo como negativo (ver Hale, 1997: 578; Monson, 1997; Wade, 1995).

\section{El gobierno local y las ONG's formales}

El gobierno local y algunas ONG's formales (i.e. que trabajan a nivel de la ciudad o del país) compartían la preocupación de los Ashanty sobre la cultura como un sitio importante de acción, pero tendían a entender la cultura como una expresión estética, como algo separado de la política, o simplemente como una mercancía. La banda tenía contactos con la oficina del alcalde para Grupos Especiales, que tenía a su vez sub-secciones que se encargaban de temas de juventud, negritud, tercera edad, y discapacidad. Los Ashanty habían solicitado

\footnotetext{
${ }^{17}$ Todos los miembros de Ashanty eran hombres. Había organizaciones de mujeres en el barrio, incluyendo una fundada por mujeres negras que luego incluyó no-negras y cuyo foco era principalmente los problemas de salud de las mujeres y las relaciones de género dentro de la familia. También había grupos de danza sólo de mujeres, aunque los que yo conocí los conformaban mujeres jóvenes y los dirigían hombres. La mayoría de grupos de rap en Cali eran masculinos; había unos pocos grupos de rap femeninos que en alguna ocasión enfrentó los problemas de sexismo, aunque no, por experiencia propia, en relación directa con el activismo negro. Aunque se dieron alusiones sesgadas con respecto a la dinámica de género de los grupos de rap negros y activismo negro relacionadas con lo sugerido por Hooks (1981) en Estados Unidos. Sin embargo, los movimientos sociales negros en general en Colombia frecuentemente son conscientes de estos problemas y las mujeres negras son activas en dichos movimientos (véase Pedrosa et al., 1996, y Rojas, 1996 para temas de género y Afrodescendencia). De igual manera, no observé en Ashanty una ostensible masculinización de lo negro como lo comenta Hookes (1981); aunque entre otros grupos de rap de Cali el seguimiento estrecho de ciertos grupos norteamericanos si llego a despertar este problema.
} 
dinero a las sub-secciones para jóvenes y negros pero se les negó; el director de la sección decía que no financiaban fiestas. Sin embargo financió, finalmente, otras bandas de rap y grupos de danza que se veían mejor organizados y más estables que los Ashanty. El dinero invertido en ellos fue considerado como un pago por tener la gente joven comprometida, fuera de las calles, lejos de las drogas, el crimen, y la violencia, y "convirtiéndolos" en buenos ciudadanos. La idea no fue invertir en una forma de vida completa en la cual "cultura" y "política" estuvieran unificadas. Por el contrario, se trataba abstraer los individuos de la política involucrándolos en la "cultura". Me parece a mi que la noción de "cultura" utilizada fue restringida a los artístico y quizás a actividades deportivas, además, a algo que tenía solidez y continuidad (cf. Clifford, 1988), a algo que no fuera tan radical en su expresión de la identidad racial. El deporte, la música, la kermés que los Ashanty organizaron no encajaban en esas definiciones de "cultura": lucían como fiestas. Aunque el concierto de rap de 1996 había recibido fondos de Desepaz, el de 1997 no: parecía demasiado "desorganizado". El hecho de que la identidad de los Ashanty fue construida alrededor de la música y el estilo, oponía al grupo con las ideas de cultura de la oficina del alcalde; esto también significó que esas actividades podrían ser consideradas efímeras. La naturaleza anárquica del rap que permitía a los grupos coincidir alrededor de una grabadora y un par de micrófonos y que con la misma facilidad que se armaban se disolvían, fue una atracción para los Ashanty y su cultura hip-bop, pero lo misma razón, esto operaba en su contra a los ojos de la alcaldía.

La oficina del Alcalde financió, por ejemplo, un grupo llamado Escorpiones Negros, liderado por un hombre negro joven quien era fan de figuras como Michael Jackson, MC Hammer, y Vanilla Ice, en vez de los más radicales Public Enemy, The Fugees, y Cipres Hill, preferidos por los Ashanty. Él fue presidente de una ONG que trabajaba en Aguablanca llamada Red Cultural, fundada y mantenida por un blanco de Bogotá y financiada por el estado regional y ONG's internacionales. Su actividad central era organizar un carnaval anual llamado La Feria de las Culturas y ayudar a otros grupos en los barrios a montar eventos similares de pequeña escala. Desde esta perspectiva, el rap y otros estilos de música y danza eran producciones más culturales u objetos que formas de vida. Quizá comulgando con esto, la Red Cultural soslayó los asuntos raciales, separando la experiencia del racismo de la música y la "cultura".

A través de su oficina cultural, la oficina del Alcalde financió a la Asociación Cultural Juventud Unidad, un grupo de jóvenes que acogió grupos de rap, salsa y rock, y grupos folclóricos de danza. Esta organización era conducida por un hombre negro, y aunque en su mayoría los miembros eran personas negras también pertenecían a la asociación una minoría no negra. En 1997 
este hombre se presentó a las elecciones como candidato para un cargo en la junta administradora local (JAL) de su barrio y me invito al lanzamiento de su campaña. Bajo la consigna puesta en pancartas $A$ l rescate de nuestra identidad - que no dejaba en claro a quién hacía referencia el "nuestra" - diversos políticos de las corrientes tradicionales prometieron su ayuda después de que se tocó el himno nacional. Siguieron presentaciones de una serie de grupos, incluyendo Poder Africano (un grupo de rap, con letras y un estilo radical), una banda especializada en covers de merengues y música de Michael Jackson, bailarines de salsa con trajes de luces (más acorde con la imagen internacional de Cali de ciudad salsera), una "papayera" (clásica agrupación de las campañas políticas colombianas), y un grupo de rock. En suma, esta asociación mucho más comercial y relacionada con el tradicional clientelismo de los partidos políticos, fue financiada por la oficina del Alcalde antes que preferir al grupo Ashanty.

La cultura que los Ashanty estaban creando no encajaba en los estándares del gobierno municipal. A los ojos de los administradores locales parecían demasiado negra, demasiado desorganizada, y demasiado efímera: no estaba lo suficientemente objetivada y mercantilizada para producir los beneficies esperados por la inversión. Para la oficina del Alcalde, como para los Ashanty, la cultura era un objeto, un producto material que también significaba una inversión. Para los Ashanty, la inversión fue en cuanto a sus actividades como un todo, y la ganancia estaba puesta en función del respeto y la autonomía de la cultura bip-bop y la identidad negra; para la oficina del Alcalde la ganancia fue ciudadanos "cultos". Podían financiarse aspectos de la "cultura negra," pero sólo aquellos que condujeran a los resultados entendidos como correctos. Los miembros de Ashanty no fueron reacios a ser "ciudadanos", pero para ellos esta tenía que incluir una noción de negritud y aún de africanía, elementos que fueron marginados por el gobierno municipal.

El punto de vista de la oficina de la Alcaldía era compartido con algunas de las ONG's de gran escala que también financiaban la "cultura." Por ejemplo, la Corporación Juan Bosco, una ONG Jesuita, tenía varios programas de trabajo social y clubes de jóvenes en Aguablanca y asimismo financiaba grupos de rap, principalmente el Cartel Cali Rap. En terreno, comprobé que la Corporación tenía buena reputación en Aguablanca y era reconocida por desarrollar servicios valiosos. En algunos aspectos, la visión de cultura adoptada por CJB era similar a la del gobierno local. En un documento esbozado para acceder a fondos del programa educativo de Desepaz dirigido a "jóvenes en alto riesgo," la CJB propuso planes para actividades "culturales" que fueron casi todas artísticas y deportivas (Corporación Juan Bosco 1997). Decisivamente hablaron de la cultura como "la antesala de nuestra tarea en los sectores populares", es decir, como una 
forma de entrar a algo distinto, un instrumento para llegar a algo más profundo. Se debía invertir en la cultura para obtener una ganancia en un nivel más profundo (resolver los problemas de criminalidad, violencia, drogadicción, etc.).

\section{Conclusiones}

Necesitamos ver la producción cultural en dos sentidos, como un proceso unificado en el cual lo material y lo simbólico son principios inseparables, y como un proceso de objetivación y mercantilización llevado a cabo de diversas maneras acorde a diferentes visiones y agendas. Haciéndolo, se llevarán más lejos los avances en la teorización de los movimientos social que han venido haciendo académicos que desafían las divisiones convencionales entra la cultura y la política. Esta aproximación a la naturaleza de la identidad cultural ayuda a reconciliar los enfoques centrados en la práctica y aquellos centrados en el discurso (Monson, 1997: 172), no simplemente combinándolos, sino viendo la práctica como inherentemente llena de sentido y el discurso como materialmente sustentado. El trabajo unificado que las personas hacen al estar en el mundo es la base para sus objetivaciones de la cultura, lo cual tiende a dividir esa unidad en dos campos y a privilegiar los símbolos. Es común para los grupos subordinados ver sus identidades y culturas como "cosas," pero estas existen en tensión con la visión de las culturas comos formas de vida en las cuales lo que hacen y lo que dicen son parte del mismo proceso. La fuerte presión de un mundo mercantilizado y alienado que ve las culturas y las identidades culturales como representaciones - sentidos y expresiones que son entendidos como separables del trabajo material, la práctica, y la acción — constituyen riegos frente a los que los antropólogos nos son inmunes, pero que pueden equilibrarse por medio de un enfoque más inclusivo.

En el estudio de caso de Cali con los Ashanty, las ONG's, y el gobierno local, se demostró que estas instituciones están hasta cierto punto de acuerdo sobre la naturaleza de la cultura. Cada actor buscaba trabajar con, hablar sobre, y encontrar dinero para mejorar, desarrollar e impulsar la cultura. Como el título de uno de uno de los ensayos de Strathern lo recuerda: "Lo agradable de la cultura es que cada uno la tiene" (Strathern, 1995). Detrás de esta premisa de igualdad, hay diferencias culturales percibidas (cultura juvenil, cultura negra, cultura hip-hop, etc.) que, una vez su naturaleza potencialmente problemática ha sido neutralizada, pueden ser cultivadas y promovidas en una sociedad "multicultural". En un nivel más profundo, existen diferencias en los objetivos de los diversos actores: promover las culturas como formas de vida o promover actividades "culturales" (artísticas) como una solución a-política para problemas de naturaleza "anti-social". Las versiones de la "cultura", de la identidad cultural 
y de Cali en sí misma, que se ajustan lo más cuidadosamente posible con las visiones dominantes, son aquellas que encuentran financiación; las demás versiones son marginadas.

En la práctica, esto significa, como diversos críticos han señalado (Fox y Stara ,1997: 9; Hale, 1997: 571) que las políticas de la identidad tienen continuidades con las políticas de clase. Por su puesto que obreros y campesinos ya no son los actores centrales que una vez fueron, y que un espacio de nuevas identidades, y el concepto de identidad mismo, se ha convertido en políticamente significativo. Sin embargo, cuando las políticas de la identidad o las políticas de la cultura son dibujadas dentro de una visión de la "cultura" como productos exclusivamente simbólicos, todo parece quedar limitado al discurso enmascarando los asuntos de clase (Hollinger, 1997; Marable, 1995: cáp. 16; Winant, 1993). Cuando se presenta la posibilidad de vivir la cultura, la tierra, y el territorio como una unidad — como muchos grupos minoritarios señalan que las viven— parece más difícil incriminar a las políticas de la identidad por desestimar asuntos básicos y complejos de clase. Las fuerzas dominantes en las sociedades en que esos grupos viven intentan fragmentar esa unidad — divorciando la cultura de la política, de lo económico, de lo religioso y así sucesivamente (o de los negros, de los jóvenes, de los discapacitados, de los adultos mayores; tal como se deduce de la sección de Grupos Especiales de la Alcaldía). Aunque persiguiendo objetivos muy diferentes, los grupos minoritarios son conducidos forzosamente a pensar sus actividades bajo estas formas hegemónicas. La antropología ha estado predispuesta tanto a contestar tales procesos de fragmentación — centrándose en la cultura como forma de vida-, como a reproducirlos al estudiar la cultura como un conjunto de productos e incluso considerándolos sólo como representaciones. Como parte de las políticas de la cultura deben reconocerse las implicaciones políticas de considerar la cultura como una unidad y entender su coexistencia contradictoria con la cultura como objeto y mercancía.

\section{Bibliografía}

- Appadurai, Arjun. 1991. "Global Ethnoscapes: Notes and Queries towards a Transnacional Anthropology”, en: Recapturing anthropology: Working in the present. Ed. Por R.G. Fox. Santa Fe School of American Researche Press.

- Arocha, Jaime. 1992. Los negros y la nueva constitución colombiana de 1991. América Negra 3:39-54. 
.1996. "Afrogénesis, eurogénesis y convivencia interétnica". en: Pacífico: ¿Desarrollo o Biodiversidad? Estado, Capitaly movimientos sociales en elpacífico colombiano. Ed. Por Arturo Escobar y Alvaro Pedrosa, Bogotá, Cerec.

. 1998. "Inclusions of Afro-Colombians: Unreachable nacional goal?", en: Latin American Perspectives 25(3):70-89.

- Bauman, Zygmunt. 1973. Cultura as praxis. London: Routledege and Kegan Paul.

- Beverley, John, y José Oviedo. 1995. "Introdution", en The postmodernism debate in Latin America. Ed. Por John Beverley, José Oviedo y Michael Aronna, pp. I-17. Durhan: Duke University Press.

-Bhabha, Homi. 1994. The location of culture. London: Routledge.

- Bourdieu, Pierre. 1977. Outline of a theory of practice. Cambridge: Cambridge University Press.

- Brown, Michael. 1998. "Can Culture be copyrighted?", en Current Anthropology 39, pp. 193-222.

- Butler, Judith. 1993. Bodies that matter: On the discursive limits of "sex." London: Routledge.

- Campbell, Colin. 1987. The romantic ethic and the spirit of modern consumerism. Oxfor: Basil Blackwell.

- Clifford, James. 1988. "Identity in Mashpee", en: The predicament of culture: Twentieth-century ethnography, literature, and art, Cambridge: Harvard University Press, pp. 277-348.

- Clifford, James y Goerge Marcus. Eds. 1986. Writing culture: the poetics and politics of ethnography. Berkeley: University of California Press.

- Comaroff, John, y Jean Comaroff. 1992. Ethnography and the historical imagination. Boulder: Westvoew Press.

- Corporación Juan Bosco. 1997. Programa Parces: Una intervención educativa con jóvenes en dificultades o en alto riesgo de las comunas 11, 12, 13, 14 y 15 de la ciudad de Cali. MS, Cali.

- Csordas, Thomas. 1994. "Introducation: The body as representation and being-in-the-world", en: Embodiment and experience: The existential ground of culture and the self. Ed. por T. Csordas, Cambridge: Cambridge University , pp. 1-24.

- Das, V. 1995. "On Soap opera: What kind of anthropological object is it?", en: Worlds Apart: Modernity Through the Prism of the Local. Ed. por Danile Miller, 
London: Routledge, pp: 169-89.

- De Certeau, Michel. 1984. The practice of everyday life. Berkeley: University of California Press.

- Escobar, Arturo. 1992. "Culture, economics, and politics in Latin American social movements theory and research", en: The making of social movements in Latin American: Identity, strategy, and democracy. Ed. por A. Escobar y Sonia Álvarez, Boudler: Westview press, pp 62-85.

- Escobar, Arturo, y Sonia Álvarez. 1992. "Introduction: Theory and protest in Latin America Today", en: The making of social movements in Latin American: Identity, strategy, and democracy. Ed. por A. Escobar y Sonia Álvarez, Boudler: Westview press, pp: 1-15.

- Featherstone, Mike. 1995. Undoing culture: globalization, postmodernism, and identity. London, Sage.

- Foweraker, Joseph. 1995. Theorizing social movements. London: Pluto Press.

- Fox, Richard, y Orin Starn. 1997. "Introduction", en: Between resistance and revolution: Cultural politics and socialprotest. Ed. por Richard Fox y Orin Starn, New Brunswick: Rutgers University Press, pp: I-17.

- Friedemann, Nina de. 1993. La saga del negro: Presencia Africana en Colombia. Bogotá: Instituto de Genética Humana, Pontificia Universidad Javeriana.

- Friedemann, Nina de, y Jamime Arocha. 1986. De sol a sol: Génesis, transformación y presencia de los negros en Colombia. Bogotá: Planeta.

- Friedman, Jonathan. 1994. Cultural identity and global process. London: Sage.

- Grueso, Libia, Carlos Rosero y Arturo Escobar, 1998. "The process of black community organizing in the southern Pacific coast of Colombia", en: Cultures of politics, politics of cultures: Re-visioning Latina American Social movements. Ed. Sonia Álvarez, Evelina Dagnino y Arturo Escobar, Boulder: Westview Press, pp. 196-219.

- Hale, Charles. 1997. "Cultural politics of identity in Latin America", en: Annual Review of Anthropology 26, pp.567-90.

- Hall, Stuart. 1980. "Race, articulation, and societies structured in dominance", en: Sociological theories: Race and colonialism. Ed. por UNESCO, Paris.

- Hollinger, David. 1997. "The disciplines and the identity debates, 19701995”, en: Daedalu 126, pp. 333-51. 
- Ingold, Tim. 1991. "Against the motion (I)", en: Human worlds are culturally constructed: $A$ debate. Ed. por Tim Ingold, Manchester: Group for debates in anthropological theory, pp. 12-17.

.1992. "Culture and the perception of the environment", en: Bush base, forest farm. Ed. por: E. Croll y D Parkin. London: Routledge. . 1995. "Building, dwelling, living: How animals and people make themselves at home in the world", en: Shifting context: transformations in anthropological knowledge. Ed. por M. Strathern, pp. 57-80. London: Routledge.

- Jackson, Jean. 1995. "Culture, genuine and spurious: The politics of Indianness in the Vaupès, Colombia”, en: American Ethnologist, 22 (1), pp. 22:3-27.

- Jackson, Michael. 1989. Paths towards a Clearing: Radical Empiricism and Ethnographic Inquiry. Bloomington: Indiana University Press.

- Kahn, Joel. 1995. Culture, Multiculture, Postculture. London:Sage.

- Lave, Jean, P. Diguid, N. Fernández, y E. Axel. 1992. "Coming of age in Birminghanm: Cultural studies and conceptions of subjectivity", en: Annual Review of Anthropology, 21, pp. 257-82.

- List, George. 1980. "Colombia: Folk music". en: New Gorve Dictionary of Music and Musicians. Vol. 4. Ed. por Stanley Sadie, London: Macmillian, pp. 570-81.

- Losonczy, Ann-Marie. 1997. Les saints et la forêt: Rituel, société et figures de l'Échange entre Noirs et Indiens Emberá (Chocó, Colombie). París: L'Harmattan.

- Marable, Manning. 1995. Beyond Black and White. London: Verso.

- Middleton, Richard. 1990. Studying Popular Music. Milton Keybes: Open University Press.

- Mintz, Sidney. 1985. Sweetness and Power: The Place of Sugar in Modern History. NY: Viking Penguin.

. 1996. "Enduring substances, trying theories: the Caribbean Region as Oikouneme". Journal of the Royal Anthropological Institute 2, pp.289311.

- Monson, Ingrid. 1997. "Abbey Lincoln's straight ahead: jazz in the era of the civil rights movement", en: Between Resistance and Revolution: Cultural Politics and Social Protest. Ed, por Richard Fox y Orin Starn, New Brunswick: Rutgers University Press, pp. 171-94.

- Moore, Henrietta. 1994. A passion for difference, Cambridge: Polity Prees. 
- Ota, Yoshinobu. 1997. "Appropriating Media, Resisting Power: Representations of. Hybrid Identities in Okinawan Popular Culture", en: Between Resistance and Revolution: Cultural Politics and Social Protest. Ed, por Richard Fox y Orin Starn, New Brunswick: Rutgers University Press, pp. 145-70.

- Pasquinelli, Carla. 1996. "The Concept of Culture between Modernity and Postmodernity", en: Grasping the Changing World: Anthropological Concepts in the Postmodern Era. Ed. por Václav Hubinger, London: Routledge, pp. 53-73.

- Pedrosa, Álvaro, et al. 1996. Movimiento negro, identidad y territorio, Entrevista con la Organización de Comunidades Negras. En: Pacifico: ¿ Desarrollo o biodiversidad? Estado, Capital, y movimientos sociales en el Pacifico colombiano. Ed. por A. Escobar y Álvaro Pedrosa. Bogotá: Cerec.

- República de Colombia. 1996. Derechos de las comunidades negras de Colombia: Compendio legislativo sobre la población afrocolombiana. Bogotá: Dirección de Asuntos para las Comunidades Negras, Ministerio del Interior y Proyecto Biopacífico.

- Restrepo, Eduardo. 1997. "Afrocolombianos, antropología y proyecto de modernidad en Colombia". En: Antropología en la modernidad: Identidades, etnicidades y movimientos sociales en Colombia, Ed. Por María Victoria Uribe y Eduardo Restrepo. Bogotá: ICANH.

- Rojas, Silva, Jeannette. 1996. "Las mujeres en movimiento: Crónicas de otras miradas", en: Pacífico: ¿Desarrollo o biodiversidad? Estado, Capital, y movimientos sociales en el Pacifico colombiano. Ed. por A. Escobar y Álvaro Pedrosa. Bogotá: Cerec.

- Roseberry, Willian. 1997. "Marx and anthropology", en Annual Review of Anthropology 26, pp.25-46.

- Sahlins, Marshall. 1976. Culture and practical reason. Chicago: University of Chicago Press.

1993. "Goodbye to Tristes Tropes: Ethnography in the context of Modern World History, en: Journal of Modern History 65, pp.1-25

- Shilling, Chris. 1993. The body and social theory. London: Sage.

- Stolcke, Verena. 1995. “Talking Culture: New Boundaries, new Rhetorics of Exclusion in Europe", en: Current Anthropology 36, p.1-23.

- Strathern, Marilyn. 1995. "The nice thing about Culture is that Everyone has it", en: Shifting context: Transformations in anthropological knowledge. Ed. por Marilyn Strathern, London: Routledge, pp. 153-76.

- Taussig, Michael. 1980. The devil and commodity fetishism in South America. 
Chapel Hill: University of North Carolina Press.

- Thompson, Kenneth. 1992. "Social Pluralism and Post-modernity", en: Modernity and its Futures. Ed. por S. Hall, D. Held, y T. McGrew. Cambridge: Polity Press.

- Tilley, Christopher. 1994. A phenomenology of landscape: Places, paths, and monuments. Oxford: Berg

- Tuan, Yi-Fu. 1977. Space and place: The perspective of experience. Londono: Arnold.

-Turner, Terence. 1991. "Representing, Resisting, Rethinking. Historical. Transformations of Kayapo Culture and Anthropological Consciousness", en: Colonial Situations: Essays on the Contextualization of Ethnographic Knowledge. Ed. por George Stocking, Madison: University of Wisconsin Press, pp. 285-313.

.1992. "Defiant Images: The Kayapo appropriation of video", en: Anthropology Today 8(6), pp. 5-16.

.1994. "Bodies and anti-bodies: Flesh and Fetish in Contemporary Social Theory, en: Embodiment and Experience: The existential ground of Culture and the Self. Ed. por T. Csordas, Cambridge University Press, pp. 27-47.

- Ulloa Sanmiguel, Alejandro. 1995. Juventud, música pop y modernidad: culturas urbanas e identidades sociales. Ms. Cali: Universidad del Valle.

- Urrea, Fernando. 1997. "Dinámica sociodemográfica, Mercado laboral y pobreza en Cali durante las décadas de los años 80 y 90”, en: Coyuntura Social 17 , pp. $105-64$.

- Urry, John. 1990. The tourist gaze: leisure and travel in contemporary societies. London: Sage.

- Wade, Peter. 1993. Blackness and Race mixture: the Dynamics of Racial Identity in Colombia. Baltimore: Johns Hopkins University Press.

.1995. "The Cultural Politics of Blackness in Colombia", en: American Ethnologist 22, pp. 342-58.

.1998. "Blackness, Music, and National Identity: Three Moments in Colombian History", en: Popular Music 17(1), pp. 1-19.

- Wagner, Roy. 1981. The invention of Culture. Chicago: University of Chicago Press.

- Waxer, Lise. 1997. Salsa, champeta, and rap: Black sounds and black identities in 
Afro-Colombia. Ponencia presentada al encuentro anual de la Sociedad para la

Ethnomusicología. Pittsburgh.

- Whitten, Norman. 1986. Black frontiersmen: A South American case. Prospect Heights: Waveland Press.

-, Norman y Arlene Torres. 1998. "General introduction: To forge the future in the fires of the past: An interpretive essay on racism, domination, resistance, and liberation", en: Blackness in Latin America and the Caribbean: Social dynamics and Cultural transformations. Vol. I. Ed. por Norman Whitten y Arlene Torres, Bloomington: Indiana University Press, pp. 3-33.

- Wilk, Richard. 1995. "Learning to be different in Belize: Global Systems of Common difference", en: World apart: Modernity through the Prism of the Local. Ed. por Daniel Miller, London: Routledge, pp. 110-33.

- Williams, Raymond. 1961. The long revolution. NY: Columbia University Press. . 1988. Keywords. London: Fontana.

- Winant, Howard. 1993. "Difference and Inequality: Postmodern Racial Politics in the United States", en: Racism, theCity, and the State. Ed. por M. Cross y M. Keith. London: Routledge.

-Wolf, Eric. 1992. Europe and the People without History. Berkeley: University of California Press.

- Wright, Sue. 1998. "The politicization of 'culture", en: Anthropology today. 14(I), pp.7-15. 
